Nancy N. Baxter, Keenan Research Centre, Li Ka Shing Knowledge Institute, St. Michael's Hospital; Nancy N. Baxter and Therese A. Stukel, University of Toronto and Institute for Clinical Evaluative Sciences, Toronto, Ontario, Canada; Joan L. Warren and V. Paul Doria-Rose, National Cancer Institute Bethesda; and Michael J. Barrett, Information Management Services, Silver Spring, MD

Submitted November 4, 2011; accepted April 23, 2012; published online ahead of print at www.jco.org on June 11, 2012

Supported by an Early Researcher Award from the Ontario Ministry of Research and Innovation (N.N.B.), by the National Cancer Institute, Bethesda, MD; the Cancer Care Ontario Health Services Research Chair, Ontario, Canada (held by N.N.B.); and by a grant from the Ontario Ministry of Health and Long-Term Care to the Institute for

Clinical Evaluative Sciences.

V.P.D.-R. and M.J.B. had full access to all of the study data and take responsibility for the integrity of the data and the accuracy of the data analysis. No endorsement by the Institute for Clinical Evaluative Sciences or the Ontario Ministry of Health and Long-Term Care is intended or should be inferred.

Authors' disclosures of potential conflicts of interest and author contributions are found at the end of this article.

Corresponding author: Nancy N. Baxter MD, PhD, Division of General Surgery,

St. Michael's Hospital, University of Toronto, 30 Bond St, 16CC-040,

Toronto, Ontario, Canada M5B 1W8 e-mail: baxtern@smh.toronto.on.ca.

(c) 2012 by American Society of Clinica Oncology

0732-183X/12/3021-2664/\$20.00 DOI: $10.1200 / J C O .2011 .40 .4772$

\title{
Association Between Colonoscopy and Colorectal Cancer Mortality in a US Cohort According to Site of Cancer and Colonoscopist Specialty
}

Nancy N. Baxter, Joan L. Warren, Michael J. Barrett, Therese A. Stukel, and V. Paul Doria-Rose

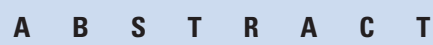

\section{Purpose}

We designed this study to evaluate the association of colonoscopy with colorectal cancer (CRC) death in the United States by site of CRC and endoscopist specialty.

\section{Methods}

We designed a case-control study using Surveillance, Epidemiology, and End Results (SEER)Medicare data. We identified patients (cases) diagnosed with CRC age 70 to 89 years from January 1998 through December 2002 who died as a result of CRC by 2007. We selected three matched controls without cancer for each case. Controls were assigned a referent date (date of diagnosis of the case). Colonoscopy performed from January 1991 through 6 months before the diagnosis/referent date was our primary exposure. We compared exposure to colonoscopy in cases and controls by using conditional logistic regression controlling for covariates, stratified by site of CRC. We determined endoscopist specialty by linkage to the American Medical Association (AMA) Masterfile. We assessed whether the association between colonoscopy and CRC death varied with endoscopist specialty.

\section{Results}

We identified 9,458 cases (3,963 proximal [41.9\%], 4,685 distal [49.5\%], and 810 unknown site [8.6\%]) and 27,641 controls. In all, $11.3 \%$ of cases and $23.7 \%$ of controls underwent colonoscopy more than 6 months before diagnosis. Compared with controls, cases were less likely to have undergone colonoscopy (odds ratio [OR], 0.40; $95 \% \mathrm{Cl}, 0.37$ to 0.43 ); the association was stronger for distal (OR, $0.24 ; 95 \% \mathrm{Cl}, 0.21$ to 0.27 ) than proximal $(\mathrm{OR}, 0.58 ; 95 \% \mathrm{Cl}, 0.53$ to 0.64$) \mathrm{CRC}$. The strength of the association varied with endoscopist specialty.

\section{Conclusion}

Colonoscopy is associated with a reduced risk of death from $\mathrm{CRC}$, with the association considerably and consistently stronger for distal versus proximal CRC. The overall association was strongest if colonoscopy was performed by a gastroenterologist.

\section{J Clin Oncol 30:2664-2669. (C) 2012 by American Society of Clinical Oncology}

\section{INTRODUCTION}

Colorectal cancer (CRC) is common worldwide; population-based screening has been proposed to reduce morbidity and mortality from CRC. Screening with fecal occult blood testing or flexible sigmoidoscopy has been demonstrated in randomized trials to be effective for reduction of CRC deaths. ${ }^{1-4}$ Despite a lack of clinical trial data establishing effectiveness, colonoscopy is the most common method of CRC screening in the United States. ${ }^{5}$ In a US survey, 95\% of primary care physicians recommended colonoscopy as the preferred CRC screening modality. ${ }^{6}$

Recently published cohort and case-control studies $^{7-15}$ confirm an association between colonoscopy and CRC incidence/mortality. These stud- ies also demonstrate greater effectiveness of colonoscopy in the distal colon and rectum versus the proximal colon; however, the mechanisms are unclear. Quality of colonoscopy may be important; poor-quality colonoscopy may reduce effectiveness, primarily in the proximal colon. Most studies were conducted outside the United States. Because, as suggested by some authors, ${ }^{16}$ the quality of colonoscopy in those studies may differ from colonoscopy in the United States, we designed this study using US data. We hypothesized that colonoscopy would be associated with decreased CRC mortality, the strength of the association would be greater for distal versus proximal cancer, and the strength of the association would vary with a surrogate marker of quality (endoscopist specialty). 


\section{METHODS}

\section{Study Design}

We designed a case-control study of the association of colonoscopy and CRC deaths. We measured odds of exposure to colonoscopy in cases (patients who died as a result of CRC) and controls (persons without cancer) and calculated an odds ratio (OR) for exposure.

\section{Data Sources}

We used Surveillance, Epidemiology, and End Results (SEER) cancer registry data linked to Medicare enrollment and utilization data. ${ }^{17}$ The National Cancer Institute-sponsored SEER program collects information on cancer incidence and survival from population-based registries in geographic areas representing $26 \%$ of the US population. ${ }^{18}$ Medicare provides health care for $97 \%$ of the US population age 65 years or older. Cancer cases reported to SEER have been matched to the Medicare enrollment file to facilitate research. ${ }^{17}$ The SEER-Medicare data include beneficiaries without cancer, derived from a random $5 \%$ sample of beneficiaries residing in SEER areas.

For Medicare patients not in managed care, SEER data and Medicare claims for hospitalizations, outpatient visits, and physician services are available. Claims submitted to Medicare using International Classification of Diseases Ninth Revision (ICD-9) procedure and diagnosis codes, Current Procedural Terminology (CPT) codes, and Healthcare Common Procedure Coding System Level II (HCPCS II) codes reflect medical services provided. Claims from outpatient facilities and physicians include Unique Physician Identification Numbers (UPIN) for providers.

\section{Cases}

We identified cases from SEER data (Fig 1) diagnosed with invasive CRC from January 1, 1998, through December 31, 2002, as their only cancer diagnosis in SEER. To identify patients who had CRC diagnosed outside SEER areas and were therefore not recognized as having CRC in the cancer registry, we excluded patients with hospital or physician claims in Medicare for CRC more than 6 months before the date of diagnosis (Appendix Table A1, online only). We included only patients who died of malignancy from January 1 , 1998 , through December 31, 2007, who were age 70 to 89 years at diagnosis. To

All patients with CRC in SEER with diagnosis date 1998-2002 $(n=118,431)$

\section{$\downarrow$}

Include only first cancer diagnosis (excludes 36,227 )

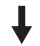

Include only invasive adenocarcinoma (excludes 6,479)

$$
\downarrow
$$

Include only those who died as a result of cancer between

January 1, 1998 and December 31, 2007 (excludes 47,731)

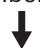

Include only those age 70-89 years at date of diagnosis (excludes 9,739)

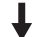

Include only those enrolled in Medicare Parts A and B from age 65 years through diagnosis and those not enrolled in managed care prior to date of diagnosis (excludes 8,312)

$$
\downarrow
$$

Include only those with no evidence of ICD-9 diagnosis of CRC at any time prior to 6 months before diagnosis (excludes 414)

Include only those with at least one matching control (excludes 71) $\downarrow$

$$
N=9,458
$$

Fig 1. Selection of cases. CRC, colorectal cancer; ICD-9, International Classification of Diseases, ninth revision; SEER, Surveillance, Epidemiology, and End Results. ensure complete Medicare claims, patients had fee-for-service coverage and were enrolled in Part A and Part B from age 65 through diagnosis. After exclusions, we identified 9,458 cases. We planned to evaluate patients by site of primary CRC as assessed by SEER registrars (proximal cancer [proximal to the splenic flexure], distal cancer [splenic flexure to rectum], or unknown site). For secondary analyses, we stratified by age, sex, and race.

\section{Controls}

From the SEER-Medicare noncancer sample, we selected people enrolled in Medicare Part A and B from age 65 years (controls). Cases and controls were matched for sex, year of birth, race, and SEER registry. For each potential matched control, we defined a date corresponding to the diagnosis date of the case, termed the "referent date." We excluded controls who were enrolled in managed care or who had evidence of CRC in hospital or physician claims before the referent date. We excluded those who died before the date of death of the matched case. We randomly selected three controls from all potential matches and assigned them to a case, forming the control group.

\section{Determining Exposure}

We identified any colonoscopy using ICD-9, CPT, and HCPCS II codes (Appendix Table A1) appearing on hospital, outpatient clinic, or physicians' claims performed from January 1, 1991, to 6 months before the date of diagnosis/referent date. Any colonoscopy performed from date of Medicare enrollment was included as an exposure; every study participant had at least 4 years of potential exposure to colonoscopy (Appendix Table A1). We treated exposure to colonoscopy as binary: those who had at least one colonoscopy were considered exposed; for patients who had more than one colonoscopy, the first colonoscopy was considered the exposure.

Screening colonoscopy was not a Medicare-covered service for most of the exposure period. To exclude those colonoscopies performed to evaluate CRC symptoms, confirm diagnosis, or search for metachronous tumor, we excluded colonoscopies done within 6 months before the date of CRC diagnosis (referent date). To validate our choice, we recalculated the $\mathrm{OR}$ for the association of colonoscopy and CRC death for windows varying from 0 to 12 months. The ORs were similar for exclusion time periods ranging from 2 to 12 months (Appendix Fig A1, online only), suggesting that the inclusion of diagnostic colonoscopies had little effect on results and that a 6-month exclusion period was reasonable, as found previously. ${ }^{9}$ Medicare colonoscopy codes require that the colonoscope is inserted past the splenic flexure. Although a code for incomplete colonoscopy exists, it is rarely used, and our exposure therefore includes complete and incomplete colonoscopies.

\section{Specialty of Colonoscopist}

We determined the UPIN of the colonoscopist from physician and outpatient files and linked this to the AMA Physician Masterfile. The AMA Masterfile ${ }^{19}$ contains data for physicians in the United States, including information on physician specialty and UPIN. We determined physician specialty on the basis of primary and secondary specialties listed in the Masterfile. We considered the endoscopist to be a gastroenterologist if the primary or secondary specialty was gastroenterology or hepatology. We considered the endoscopist to be a surgeon if general surgery, colorectal surgery, abdominal surgery, or surgical oncology were the primary or secondary specialty. We classified an individual as a primary care provider if that person had a primary or secondary specialty of internal medicine, family practice, general practice, or geriatrics but not gastroenterology. For UPINs not matched to AMA data, we used provider specialty reported on the Medicare claim for the colonoscopy, classified in the same way. Providers not meeting these definitions were classified as "other."

\section{Determining Covariates}

We controlled for factors potentially related to both CRC mortality and colonoscopy access. We determined comorbidities from diagnoses in hospital, physician, and outpatient files from 2 years to 1 month before the diagnosis/ referent date. Comorbidities were classified by using comorbidities related to CRC mortality from Klabunde's comorbidity measurement algorithm for claims-based studies ${ }^{20}$ (we did not use an index; instead, we entered comorbidities directly into our models). Socioeconomic status was based on the 
median income at the ZIP code level, categorized in quintiles. Level of urbanicity was determined from the SEER file.

\section{Statistical Analysis}

We calculated descriptive statistics by case-control status. We performed conditional logistic regression, adjusting for individual comorbid conditions, socioeconomic status, and urban/rural status to calculate the adjusted OR for the association between colonoscopy and CRC death with 95\% CIs, overall and stratified by cancer site. In a secondary analysis, we determined ORs between colonoscopy and CRC death according to provider specialty (gastroenterologist, surgeon, primary care provider, and other/missing $v$ no colonoscopy). We then assessed whether CRC death was lower for gastroenterologists versus all other providers among individuals who underwent colonoscopy by directly comparing these corresponding ORs using a contrast statement (STATA, College Station, TX). We fit models stratified by sex, age (70 to 75 or $>75$ years), and race (white, black, other) to determine whether the association was consistent between these groups.

With the exception of the STATA analysis, data were analyzed by using SAS, version 9.2 (SAS Institute, Cary, NC). All statistical tests were two-sided. The SEER-Medicare data are classified as exempt by the National Institute of Health's Office of Human Subjects Research.

\section{RESULTS}

We identified 9,458 cases (Fig 1) and selected 27,641 controls. For 431 cases, only two matching controls could be identified. For 151 cases, only one control could be matched. Median age at diagnosis was 80 years, and $57.4 \%$ of participants were women (Table 1). Colonoscopy data were available for a median of 9.4 years before diagnosis/referent date; 7,619 participants $(20.5 \%)$ had a colonoscopy more than 6 months before the diagnosis/referent date.

CRC was proximal in 3,963 (41.9\%), distal in 4,685 (49.5\%), and unknown in $810(8.6 \%)$ of cases. A total of 1,073 cases $(11.3 \%)$ and 6,546 controls $(23.7 \%)$ had colonoscopy more than 6 months before the diagnosis/referent date. Rate of colonoscopy in cases varied by tumor site (7.1\%, distal; 15.7\%, proximal; and 14.7\%, unknown CRC site). The rate of colonoscopy in matched controls did not vary by site of primary CRC in the matched case $(23.7 \%$, distal; $23.7 \%$, proximal; and $23.4 \%$ unknown site in controls matched to cases). Most colonoscopies $(65.3 \%)$ were performed by gastroenterologists (Table 1). Cases were less likely than controls to have undergone colonoscopy (adjusted conditional OR, 0.40 ; 95\% CI, 0.37 to 0.43 ; $P<.001$; Table 2 ); however, the association differed by site of primary CRC. The association was stronger for distal CRC (OR, 0.24; 95\% CI, 0.21 to 0.27 ) than for proximal CRC (OR, $0.58 ; 95 \% \mathrm{CI}, 0.53$ to 0.64$)$ or for cancer of unknown site (OR, 0.54; 95\% CI, 0.43 to 0.68). In stratified analysis, the association between colonoscopy and the risk of CRC death was weaker in women $(\mathrm{OR}, 0.44)$ and older individuals $(0.45$; Table 3). There was a reduced risk of CRC death with colonoscopy irrespective of provider specialty (Table 4); however, the association was not uniform and was stronger if colonoscopy was performed by a gastroenterologist (OR, 0.35 ; 95\% CI, 0.32 to 0.39 ) versus a surgeon (OR, $0.55 ; 95 \% \mathrm{CI}, 0.47$ to 0.64 ) or a primary care provider (OR, 0.43 ; $95 \% \mathrm{CI}, 0.33$ to 0.55$)$. In direct comparison, colonoscopy performed by a gastroenterologist was significantly more protective for CRC death than colonoscopy performed by other providers (OR for colonoscopy performed by gastroenterologists $v$ other specialties, $0.71 ; 95 \%$ CI, 0.62 to 0.81 ).

\begin{tabular}{|c|c|c|c|c|}
\hline \multirow[b]{2}{*}{ Characteristic } & \multicolumn{2}{|c|}{$\begin{array}{c}\text { Cases } \\
(\mathrm{n}=9,458)\end{array}$} & \multicolumn{2}{|c|}{$\begin{array}{c}\text { Controls } \\
(n=27,641)\end{array}$} \\
\hline & No. & $\%$ & No. & $\%$ \\
\hline \multicolumn{5}{|l|}{ Age, years } \\
\hline Median & \multicolumn{2}{|c|}{79.9} & \multicolumn{2}{|c|}{79.8} \\
\hline Range & \multicolumn{2}{|c|}{ 70.0-89.9 } & \multicolumn{2}{|c|}{$69.1-90.8$} \\
\hline Women & 5,432 & 57.4 & 15,986 & 57.8 \\
\hline \multicolumn{5}{|l|}{ Socioeconomic status, $\$^{*}$} \\
\hline Quintile $1(\leq 32,465)$ & 1,835 & 19.4 & 5,332 & 19.3 \\
\hline Quintile $2(32,466-39,906)$ & 1,782 & 18.8 & 5,410 & 19.6 \\
\hline Quintile $3(39,907-48,544)$ & 1,849 & 19.6 & 5,333 & 19.3 \\
\hline Quintile $4(48,545-60,942)$ & 1,830 & 19.3 & 5,335 & 19.3 \\
\hline Quintile $5(\geq 60,943)$ & 1,767 & 18.7 & 5,405 & 19.6 \\
\hline Unknown & 395 & 4.2 & 826 & 3.0 \\
\hline \multicolumn{5}{|l|}{ Cumulative comorbidities } \\
\hline $0-1$ & 7,237 & 76.5 & 21,723 & 78.6 \\
\hline $2-3$ & 1,741 & 18.4 & 4,626 & 16.7 \\
\hline$>3$ & 480 & 5.1 & 1,292 & 4.7 \\
\hline \multicolumn{5}{|l|}{ Race } \\
\hline White & 8,275 & 87.5 & 24,388 & 88.2 \\
\hline Black & 784 & 8.3 & 2,165 & 7.8 \\
\hline Other & 385 & 4.1 & 1,064 & 3.9 \\
\hline Unknown & 14 & 0.15 & 24 & 0.09 \\
\hline \multicolumn{5}{|l|}{ Urban/rural status } \\
\hline $\begin{array}{l}\text { Metropolitan area with population } \\
\quad \geq 1 \text { million }\end{array}$ & 5,036 & 53.3 & 13,947 & 50.5 \\
\hline $\begin{array}{l}\text { Metropolitan area with population } \\
<1 \text { million }\end{array}$ & 2,674 & 28.3 & 8,091 & 29.3 \\
\hline Urban area with population $>20,000$ & 661 & 7.0 & 1,975 & 7.1 \\
\hline \multicolumn{5}{|l|}{ Urban area with population } \\
\hline 2,500-19,999 & 910 & 9.6 & 2,866 & 10.4 \\
\hline Rural & 176 & 1.9 & 708 & 2.6 \\
\hline Unknown & & $\leq 0.2$ & & $\leq 0.2$ \\
\hline \multicolumn{5}{|l|}{$\begin{array}{l}\text { Time of observation before date of } \\
\text { diagnosis/referent date, months }\end{array}$} \\
\hline Median & \multicolumn{2}{|c|}{113} & \multicolumn{2}{|c|}{113} \\
\hline Range & \multicolumn{2}{|c|}{$61-144$} & \multicolumn{2}{|c|}{$50-144$} \\
\hline \multicolumn{5}{|l|}{$\begin{array}{l}\text { Undergoing any colonoscopy } \geq 6 \\
\text { months before date of diagnosis/ } \\
\text { referent date }\end{array}$} \\
\hline Any colonoscopy & 1,073 & 11.3 & 6,546 & 23.7 \\
\hline Colonoscopy by a gastroenterologist & 629 & 6.7 & 4,347 & 15.7 \\
\hline Colonoscopy by a surgeon & 220 & 2.3 & 998 & 3.6 \\
\hline $\begin{array}{l}\text { Colonoscopy by a primary care } \\
\text { physician }\end{array}$ & 75 & 0.8 & 445 & 1.6 \\
\hline Colonoscopy, provider unknown/other & 149 & 1.6 & 756 & 2.7 \\
\hline \multicolumn{5}{|l|}{ Site of cancer at diagnosis } \\
\hline Proximal & 3,963 & 41.9 & & \\
\hline Distal & 4,685 & 49.5 & & \\
\hline Unknown & 810 & 8.6 & & \\
\hline
\end{tabular}

*Socioeconomic status is measured by income quintile, based on the mean household income of the enumeration area of residence.

\section{DISCUSSION}

In our large, US population-based case-control study, colonoscopy was associated with an OR of 0.40 (95\% CI, 0.37 to 0.43 ) for CRC mortality, indicating a substantial protective effect. The association was considerably stronger for distal CRC (OR, 0.24; 95\% CI, 0.21 to 0.27 ) than for cancers elsewhere; however, the protective association with proximal CRC (OR, 0.58; 95\% CI, 0.53 to 0.64 ) and CRC of 


\begin{tabular}{|c|c|c|c|c|c|c|c|c|}
\hline \multirow[b]{2}{*}{ Colonoscopy Status } & \multicolumn{2}{|c|}{ All Cancers } & \multicolumn{2}{|c|}{ Proximal Cancer } & \multicolumn{2}{|c|}{ Distal Cancer } & \multicolumn{2}{|c|}{ Unknown Site of Cancer } \\
\hline & OR & $95 \% \mathrm{Cl}$ & OR & $95 \% \mathrm{Cl}$ & OR & $95 \% \mathrm{Cl}$ & OR & $95 \% \mathrm{Cl}$ \\
\hline No colonoscopy & 1.00 & & 1.00 & & 1.00 & & 1.00 & \\
\hline Any colonoscopy & 0.40 & 0.37 to 0.43 & 0.58 & 0.53 to 0.64 & 0.24 & 0.21 to 0.27 & 0.54 & 0.43 to 0.68 \\
\hline
\end{tabular}

unknown site (OR, 0.54, 95\% CI, 0.43 to 0.68 ) indicate a clinically meaningful reduction in risk of CRC death with colonoscopy throughout the colon and rectum. The association between colonoscopy and the risk of CRC death was weaker in women and older individuals, groups more likely to have proximal $\mathrm{CRC}^{21,22}$ than men or younger individuals.

There have been many recent case-control studies ${ }^{8-10,13-15}$ and cohort studies $^{11,12}$ evaluating the association of colonoscopy with incidence and mortality from CRC; our findings are consistent with these studies. Case-control studies that use a mortality end point report OR for mortality from CRC associated with colonoscopy ranging from 0.45 (95\% CI, 0.20 to 0.98$)$ in the Netherlands ${ }^{8}$ to 0.69 (95\% CI, 0.63 to 0.74 ) in Ontario, Canada. ${ }^{9}$ Cohort studies demonstrate similar findings. A stronger association between colonoscopy and CRC has been demonstrated when CRC incidence is the end point of interest. ${ }^{10,13,23}$ A recent case-control study from Germany ${ }^{15}$ found the OR for CRC incidence associated with colonoscopy was 0.19 (95\% CI, 0.16 to 0.23 ). Many factors may account for the wide range in estimates of colonoscopy effectiveness. First, colonoscopy may have greater impact on CRC incidence than mortality; cancers developing from the adenoma to carcinoma sequence in an indolent fashion may be easier to detect and prevent than aggressive cancers that rapidly progress or develop de novo-an example of length time bias. ${ }^{24}$ The proportion of individuals in the control group who underwent colonoscopy in these studies ranges from $2.2 \%^{8}$ to $41 \%^{13}$; in our study, a relatively high proportion of the control group (24\%) underwent colonoscopy. In populations with low baseline rates of colonoscopy, individuals undergoing colonoscopy may have higher risk of CRC incidence or mortality (for example, due to family history ${ }^{25}$ ) than those not undergoing colonoscopy. A study of colonoscopy effectiveness conducted in such a population may result in an estimate biased toward the null. In contrast, in populations with high rates of colonoscopy, those not undergoing screening may systematically differ from those screened in ways that increase the risk of CRC incidence and/or CRC death. For example, individuals with a healthy lifestyle may be more likely to undergo screening but may be at a lower risk of CRC than individuals not undergoing screening. ${ }^{26}$ A study conducted in such a

\begin{tabular}{|c|c|c|c|c|c|c|c|c|}
\hline Variable & OR & $95 \% \mathrm{Cl}$ & OR & $95 \% \mathrm{Cl}$ & OR & $95 \% \mathrm{Cl}$ & OR & $95 \% \mathrm{Cl}$ \\
\hline \multicolumn{9}{|l|}{ Age at diagnosis, years } \\
\hline No colonoscopy & 1.00 & & 1.00 & & 1.00 & & 1.00 & \\
\hline Any colonoscopy & 0.28 & 0.24 to 0.33 & 0.43 & 0.34 to 0.53 & 0.16 & 0.12 to 0.21 & 0.45 & 0.26 to 0.77 \\
\hline Any colonoscopy & 0.45 & 0.42 to 0.49 & 0.64 & 0.57 to 0.71 & 0.27 & 0.24 to 0.31 & 0.58 & 0.45 to 0.75 \\
\hline \multicolumn{9}{|l|}{ Female } \\
\hline No colonoscopy & 1.00 & & 1.00 & & 1.00 & & 1.00 & \\
\hline Any colonoscopy & 0.44 & 0.40 to 0.48 & 0.62 & 0.55 to 0.70 & 0.24 & 0.21 to 0.29 & 0.65 & 0.49 to 0.86 \\
\hline \multicolumn{9}{|l|}{ Male } \\
\hline No colonoscopy & 1.00 & & 1.00 & & 1.00 & & 1.00 & \\
\hline \multicolumn{9}{|l|}{ Black } \\
\hline No colonoscopy & 1.00 & & 1.00 & & 1.00 & & 1.00 & \\
\hline Any colonoscopy & 0.47 & 0.36 to 0.61 & 0.62 & 0.42 to 0.90 & 0.32 & 0.21 to 0.49 & 0.58 & 0.23 to 1.48 \\
\hline \multicolumn{9}{|l|}{ Other race } \\
\hline No colonoscopy & 1.00 & & 1.00 & & 1.00 & & 1.00 & \\
\hline Any colonoscopy & 0.38 & 0.25 to 0.57 & 0.53 & 0.28 to 0.99 & 0.26 & 0.14 to 0.50 & 0.13 & 0.01 to 1.83 \\
\hline
\end{tabular}




\begin{tabular}{|c|c|c|c|c|c|c|c|c|}
\hline \multirow[b]{2}{*}{ Variable } & \multicolumn{2}{|c|}{ All Cancers } & \multicolumn{2}{|c|}{ Proximal Cancer } & \multicolumn{2}{|c|}{ Distal Cancer } & \multicolumn{2}{|c|}{$\begin{array}{c}\text { Unknown Site of } \\
\text { Cancer }\end{array}$} \\
\hline & OR & $95 \% \mathrm{Cl}$ & OR & $95 \% \mathrm{Cl}$ & OR & $95 \% \mathrm{Cl}$ & OR & $95 \% \mathrm{Cl}$ \\
\hline No colonoscopy & 1.00 & & 1.00 & & 1.00 & & 1.00 & \\
\hline \multicolumn{9}{|c|}{ Any colonoscopy performed by: } \\
\hline Gastroenterologist & 0.35 & 0.32 to 0.39 & 0.52 & 0.46 to 0.59 & 0.20 & 0.17 to 0.23 & 0.47 & 0.35 to 0.62 \\
\hline Surgeon & 0.55 & 0.47 to 0.64 & 0.74 & 0.59 to 0.91 & 0.35 & 0.27 to 0.45 & 0.99 & 0.62 to 1.59 \\
\hline Primary care physician & 0.43 & 0.33 to 0.55 & 0.63 & 0.45 to 0.90 & 0.24 & 0.15 to 0.36 & 0.85 & 0.42 to 1.74 \\
\hline Other/unknown & 0.48 & 0.40 to 0.57 & 0.72 & 0.56 to 0.92 & 0.32 & 0.24 to 0.43 & 0.38 & 0.20 to 0.71 \\
\hline
\end{tabular}

Abbreviations: CRC, colorectal cancer; OR, odds ratio.

${ }^{*}$ Conditional logistic regression, adjusted for comorbidities, socioeconomic status, and urban/rural status.

population may result in an overestimation of the association between colonoscopy and CRC incidence and/or mortality.

Effectiveness of colonoscopy is dependent on detection and removal of cancer precursors and early detection of cancers. ${ }^{27}$ Poorquality colonoscopy may result in failure to evaluate the entire colon or failure to detect cancer precursors. Many organizations ${ }^{16}$ and individuals ${ }^{28,29}$ have proposed inadequate performance as an explanation of the weaker-than-expected association between colonoscopy and CRC death found in the Canadian case-control study. ${ }^{9}$ Our study provides evidence to support a relationship between quality of colonoscopy and effectiveness; the association of colonoscopy with CRC mortality varied according to the specialty of the colonoscopist. The association was significantly stronger for colonoscopy performed by a gastroenterologist; gastroenterologists receive more extensive colonoscopy training during fellowship than physicians with other specialties. ${ }^{30}$ Given that colonoscopy is a complex skill with a long learning curve, quality of gastroenterologist-provided colonoscopy may be higher on average than colonoscopy provided by other providers, although at the individual level, there will be poor-quality performers who are gastroenterologists and high-quality performers who are not gastroenterologists. The relationship between provider specialty and colonoscopy effectiveness is supported by the literature. In the US Medicare population, colonoscopy performed by a gastroenterologist was more likely to result in the removal of polyps than colonoscopy performed by providers who are not gastroenterologists. ${ }^{31}$ Other authors have demonstrated an increased risk of CRC development within 3 years of colonoscopy performed by a provider who is not a gastroentologist. ${ }^{32,33}$

All observational studies, including ours, are at risk of confounding by unmeasured factors, and it is not possible to determine a precise estimate of the effectiveness of colonoscopy from such studies. However, the overall consistency of the literature is compelling; colonoscopy is effective for prevention of CRC mortality. Our study also demonstrated a marked difference in the strength of the association of colonoscopy with CRC death for proximally and distally located cancers, another remarkably consistent finding. ${ }^{9-13,15,34}$ What underlies this? Again, quality of colonoscopy has been proposed as a major mechanism ${ }^{13,16,35}$; however, our study demonstrates the relative difference in the strength of the association between colonoscopy and CRC mortality from proximal and distal cancers to be similar for gastroenterologists and providers who are not gastroenterologists. There are underlying differences in the biology of proximal and distal CRC neoplasia that may contribute to the variable effectiveness of colonoscopy. Proximal adenomas are often flat ${ }^{36}$ and harder to identify than pedunculated polyps that predominate distally. In addition, distal cancers are more likely to develop through the chromosomal instability pathway with the classic slow progression of adenoma to carcinoma ${ }^{36}$ than proximal colon cancers, potentially providing greater opportunity for colonoscopic detection.

We did not know the indication for colonoscopy. Since colonoscopy for CRC screening indications was not routinely reimbursed by Medicare before 2001, most colonoscopies in our study were performed for diagnostic purposes. To exclude colonoscopy performed for signs and/or symptoms of CRC resulting in a diagnosis, we included only colonoscopy performed more than 6 months before CRC diagnosis, an approach consistent with that of other studies in the literature. ${ }^{9}$ However, screening colonoscopies resulting in an immediate diagnosis of cancer were also excluded, potentially resulting in an overestimation of the strength of the association between colonoscopy and CRC mortality. ${ }^{37}$ The time period of exposure was chosen to ensure a sufficient time for follow-up after CRC diagnosis in the cases, and it is unclear how the change in Medicare reimbursement policy may have influenced our results. Of note, the proportion of colonoscopic procedures in the Medicare population associated with polypectomy did not change substantially between $1999^{38}$ and $2003,{ }^{31}$ indicating a similar CRC risk profile during this time period.

Lifestyle factors may be other important unmeasured confounders - individuals with a healthy lifestyle may be more likely to undergo colonoscopy despite being at a lower risk of death from CRC. More significantly, our study was not able to determine family history; individuals with a family history of CRC may be more likely to die of CRC and more likely to undergo colonoscopy. However, the cases for our study were diagnosed with CRC at a relatively advanced age, and thus confounding by family history is less likely to substantially influence our analysis. The age of cases was selected to ensure sufficient time to consider exposure to colonoscopy before diagnosis. We included any colonoscopy recorded in Medicare 6 months or more before the diagnosis/referent date as an exposure. Although cases and controls may have undergone colonoscopy prior to Medicare eligibility, the median time of potential exposure in our data was 113 months, and all cases and controls had a minimum of 5 years of potential exposure. We found that colonoscopy was a common procedure in our control group; 24\% were exposed to colonoscopy and 
thus, at a minimum, our findings have important implications for those age 65 years and older.

Our study confirms that colonoscopy is effective for the prevention of CRC deaths in a US setting and that effectiveness is lower in the proximal colon. These findings have implications for cost-effectiveness analyses of CRC screening practices, particularly those comparing colonoscopy and flexible sigmoidoscopy. ${ }^{39}$ Our study also supports a growing body of literature demonstrating a relationship between specialized training in colonoscopy and effectiveness. Given the expense and risks associated with screening colonoscopy, ensuring quality through training, credentialing, and direct measurement should be an essential component of any CRC screening program.

\section{REFERENCES}

1. Scholefield JH, Moss S, Sufi F, et al: Effect of faecal occult blood screening on mortality from colorectal cancer: Results from a randomised controlled trial. Gut 50:840-844, 2002

2. Hardcastle JD, Chamberlain JO, Robinson $\mathrm{MH}$, et al: Randomised controlled trial of faecaloccult-blood screening for colorectal cancer. Lancet 348:1472-1477, 1996

3. Atkin WS, Edwards R, Kralj-Hans I, et al: Onceonly flexible sigmoidoscopy screening in prevention of colorectal cancer: A multicentre randomised controlled trial. Lancet 375:1624-1633, 2010

4. Segnan N, Armaroli P, Bonelli L, et al: Once-only sigmoidoscopy in colorectal cancer screening: Follow-up findings of the Italian Randomized Controlled TrialSCORE. J Natl Cancer Inst 103:1310-1322, 2011

5. Meissner HI, Breen N, Klabunde $\mathrm{CN}$, et al: Patterns of colorectal cancer screening uptake among men and women in the United States. Cancer Epidemiol Biomarkers Prev 15:389-394, 2006

6. Klabunde CN, Lanier D, Nadel MR, et al: Colorectal cancer screening by primary care physicians: Recommendations and practices, 2006-2007. Am J Prev Med 37:8-16, 2009

7. Kahi CJ, Imperiale TF, Juliar BE, et al: Effect of screening colonoscopy on colorectal cancer incidence and mortality. Clin Gastroenterol Hepatol 7:770-775, 2009

8. Mulder SA, van Soest EM, Dieleman JP, et al: Exposure to colorectal examinations before a colorectal cancer diagnosis: A case-control study. Eur J Gastroenterol Hepatol 22:437-443, 2010

9. Baxter NN, Goldwasser MA, Paszat LF, et al: Association of colonoscopy and death from colorectal cancer. Ann Intern Med 150:1-8, 2009

10. Brenner $H$, Hoffmeister $M$, Arndt $V$, et al: Protection from right- and left-sided colorectal neoplasms after colonoscopy: Population-based study. J Natl Cancer Inst 102:89-95, 2010

11. Singh $H$, Turner $D$, Xue L, et al: Risk of developing colorectal cancer following a negative colonoscopy examination: Evidence for a 10-year interval between colonoscopies. JAMA 295:2366-2373, 2006

12. Singh $H$, Nugent $Z$, Demers $A A$, et al: The reduction in colorectal cancer mortality after colonoscopy varies by site of the cancer. Gastroenterology 139:1128-1137, 2010

13. Brenner $\mathrm{H}$, Chang-Claude J, Seiler $\mathrm{CM}$, et al: Protection from colorectal cancer after colonoscopy:
AUTHORS' DISCLOSURES OF POTENTIAL CONFLICTS OF INTEREST

The author(s) indicated no potential conflicts of interest.

\section{AUTHOR CONTRIBUTIONS}

Conception and design: Nancy N. Baxter, Joan L. Warren, Therese A.

Stukel, V. Paul Doria-Rose

Collection and assembly of data: Michael J. Barrett

Data analysis and interpretation: Nancy N. Baxter, Joan L. Warren,

Michael J. Barrett, Therese A. Stukel, V. Paul Doria-Rose

Manuscript writing: All authors

Final approval of manuscript: All authors
A population-based, case-control study. Ann Intern Med 154:22-30, 2011

14. Brenner $H$, Haug $U$, Arndt $V$, et al: Low risk of colorectal cancer and advanced adenomas more than 10 years after negative colonoscopy. Gastroenterology 138:870-876, 2010

15. Brenner $\mathrm{H}$, Chang-Claude J, Seiler CM, et al: Long-term risk of colorectal cancer after negative colonoscopy. J Clin Oncol 29:3761-3767, 2011

16. American Society for Gastrointestinal Endoscopy: ASGE Urges Patients to Seek a Qualified Endoscopist Before Undergoing a Colonoscopy for Colorectal Cancer. Press release. Oak Brook, IL, December 16, 2008. http://www.asge.org/press/ press.aspx? $\mathrm{id}=6024$

17. National Cancer Institute: SEER-Medicare Linked Database. http://healthservices.cancer.gov/ seermedicare/

18. National Cancer Institute: Surveillance, Epidemiology, and End Results Program. http://seer.cancer .gov/

19. American Medical Association: Physician Data Resources, AMA Physician Masterfile. http:// www.ama-assn.org/ama/pub/about-ama/physiciandata-resources/physician-masterfile.page

20. Klabunde CN, Legler JM, Warren JL, et al: A refined comorbidity measurement algorithm for claims-based studies of breast, prostate, colorectal, and lung cancer patients. Ann Epidemiol 17:584590, 2007

21. Rim SH, Seeff $L$, Ahmed $F$, et al: Colorectal cancer incidence in the United States, 1999-2004: An updated analysis of data from the National Program of Cancer Registries and the Surveillance, Epidemiology, and End Results Program. Cancer 115:1967-1976, 2009

22. Wu X, Cokkinides V, Chen VW, et al: Associations of subsite-specific colorectal cancer incidence rates and stage of disease at diagnosis with county-level poverty, by race and sex. Cancer 107: 1121-1127, 2006

23. Singh G, Mannalithara $A$, Wang $H J$, et al: Is protection against colorectal cancer good enough: $A$ comparison between sigmoidoscopy and colonoscopy in the general population. Gastroenterology 132:A81, 2007

24. Kafadar K, Prorok PC: Effect of length biased sampling of unobserved sojourn times on the survival distribution when disease is screen detected. Stat Med 28:2116-2146, 2009

25. McQueen A, Vernon SW, Myers RE, et al: Correlates and predictors of colorectal cancer screening among male automotive workers. Cancer Epidemiol Biomarkers Prev 16:500-509, 2007

26. Sewitch MJ, Fournier C, Ciampi A, et al: Adherence to colorectal cancer screening guidelines in Canada. BMC Gastroenterol 7:39, 2007

27. Hewett DG, Kahi CJ, Rex DK: Does colonoscopy work? J Natl Compr Canc Netw 8:67-76, 2010

28. Triadafilopoulos G: Screening colonoscopy for colorectal cancer: Imperfect but still essential. Gastroenterology 136:1827-1828, 2009

29. Karlitz JJ: The effectiveness of colonoscopy in reducing mortality from colorectal cancer. Ann Intern Med 150:816, 2009; author reply 819-820

30. American College of Gastroenterology (ASGE): ASGE, AASLD, ACG, and AGA Statement Regarding the ABS Mandate for Surgery Residency Training in Endoscopy. September 12, 2011. http://www.asge.org/ uploadedFiles/Pressroom/JointSocietyABSTraining Statement2011.pdf

31. Ko CW, Dominitz JA, Green $P$, et al: Specialty differences in polyp detection, removal, and biopsy during colonoscopy. Am J Med 123:528-535, 2010

32. Singh $H$, Nugent $Z$, Mahmud SM, et al: Predictors of colorectal cancer after negative colonoscopy: A population-based study. Am J Gastroenterol 105:663-673, 2010

33. Rabeneck L, Paszat LF, Saskin R: Endoscopist specialty is associated with incident colorectal cancer after a negative colonoscopy. Clin Gastroenterol Hepatol 8:275-279, 2010

34. Brenner $\mathrm{H}$, Chang-Claude J, Seiler CM, et al: Does a negative screening colonoscopy ever need to be repeated? Gut 55:1145-1150, 2006

35. Lieberman D: Colon cancer screening and surveillance controversies. Curr Opin Gastroenterol 25:422-427, 2009

36. Bianco MA, Cipolletta $L$, Rotondano $G$, et al: Prevalence of nonpolypoid colorectal neoplasia: An Italian multicenter observational study. Endoscopy 42:279-285, 2010

37. Weiss NS: Analysis of case-control studies of the efficacy of screening for cancer: How should we deal with tests done in persons with symptoms? Am J Epidemiol 147:1099-1102, 1998

38. Cooper GS, Chak A, Koroukian S: The polyp detection rate of colonoscopy: A national study of Medicare beneficiaries. Am J Med 118:1413, 2005

39. Neugut Al, Lebwohl B: Colonoscopy vs sigmoidoscopy screening: Getting it right. JAMA 304: 461-462, 2010 